\title{
Rape survivor care crisis - mines the worst?
}

The dire need for better healthcare worker training in rape forensics and safe survivor care has never been better illustrated than by the horrifying rape statistics Médecins Sans Frontières (MSF) presented last month from the platinum-mining boom town of Rustenburg.

Promising to increase its rape survivor care and forensic support beyond the 120 nurses it has just trained there, MSF revealed that a quarter of all women reported being raped during their lifetimes. Dr Sarah-Jane Steele, an epidemiologist who led the rape and intimate partner violence survey of 2530 households (900 women) in November and December last year, was answering questions at an MSF Scientific Day held at the University of the Witwatersrand on 9 June.

She said that one of the MSF recommendations following the probe into sexual violence (with its implications for service provision and prevention in Rustenburg) was that the low healthcare worker awareness on how to handle rape survivors be urgently quantified. Her main concern, however, was the low reporting of patients to relevant support structures. Steele was asked what the levels of rape survivor referral and linkage were outside of the relatively few local Thutuzela and Rape Crisis-staffed healthcare facilities. A fuller MSF analysis would be available this August, but the 120 nurses they trained would be assessed for knowledge gain, while more training was planned. 'We want to get away from just one-day training to building around forensics and survivor care, she added.

Not only had $25 \%$ of all woman surveyed been raped: if this was generalised to the 247780 women living in the entire Rustenburg municipality, it would mean that 48217 women were raped (including forced sexual acts). The specific survey found $28 \%$ of women were raped by their sexual partner with a fifth of them telling nobody about it until her team came along. Steele said that these represented some of the highest estimates for both partner and non-partner sexual violence in sub-Saharan Africa.

A full $75 \%$ of survivors had been forced to have sex, while the rest of the victims felt scared or degraded, but were not forced. Tragically few women and girls knew what their treatment options were, and only $50 \%$ knew that HIV infection could be prevented. The findings have led to the study being described as a potential 'canary in a coalmine' given the lack of similar studies in migrantworker mining towns elsewhere, pointing to a dire need for training of healthcare workers in prevention and treatment in similar settings. The average age of the women surveyed was 32 years, and the antenatal HIV prevalence was $35 \%$.

Rustenburg has a predominantly migrant labour force and is uniquely male in South African mining town terms (65\% male), women usually outnumbering men. The municipal population, currently estimated at 550000 , grew by $80 \%$ between 1996 and 2011. A total of 11113 women per year were raped by a partner, the survey found. Steele said that for the purposes of the survey, rape was defined in World Health Organization terms, i.e. forced to have sexual intercourse or perform unwanted sexual act/s with a non-partner, prior sexual partner or current partner. 'Current' was defined as in the previous 12 months and 'prior' as prior to that period.

\section{Chris Bateman \\ chrisb@hmpg.co.za}

$S$ Afr Med J 2016;106(8):748.

DOI:10.7196/SAMJ.2016.v106i8.11231 